\title{
PERSPECTIVAS DO DIREITO ADMINISTRATIVO NO PRÓXIMO MILÊNIO
}

O Direito Administrativo surgiu como disciplina jurídica autônoma em época relativamente recente. Até a reforma política decorrente da Revolução Francesa não se podia caracterizar a independência científica dos preceitos reguladores da atividade administrativa do Estado. Por certo, muito antes desse marco cronológico existiam normas jurídicas sobre a organização e execução de serviços públicos. Faltava-lhes, porém, a unidade de tratamento, de objeto e de método. É evidente que a tarefa administrativa precedeu ao Direito Administrativo. Todo grupo social, mesmo primitivo e embrionário, exerce funções de administração. A disciplina da vida comum, as necessidades essenciais de defesa e manutenção da coletividade conduzem a um processo administrativo, embora rudimentar. Não se encontra, porém, na disciplina dessas relações a subordinação simultânea do indivíduo e do Estado ao império da lei.

Nos Estados absolutos, em que a vontade do soberano era a última lei, não havia clima para a formação do Direito Administrativo. A Administração não se submetia a regras e condições limitativas e flutuava ao sabor da conveniência política ou dos ditames pessoais da suprema autoridade do Estado.

A juridicidade da administração pública é fruto do liberalismo político. Os direitos do homem geram os deveres do Estado. Nos regimes absolutos, o administrador — veículo da vontade do soberano - é, como este, irresponsável. A administração é, apenas, uma técnica a serviço de privilégios de nascimento. O Estado de Direito, ao contrário, submete o Poder ao domínio da Lei: a atividade arbitrária se transforma em atividade jurídica.

No depoimento de ZANOBINI, a certidão de nascimento do Direito Administrativo terá sido a lei de 28 pluviose do ano VIII (1800) que, pela primeira vez, atribuiu à administração francesa uma organização juridicamente garantida e exteriormente obrigatória (Corso di Diritto Amministrativo - $1^{\circ}$ volume - 1947 - p. 33). Outro antecedente terá sido o emprego pioneiro da referência a "ato da administração", na 
lei de 16 do fructidor do ano III (1796) e a inclusão do vocábulo "ato administrativo" no Repertório de MERLIN, em 1812 (LUIGI RAGGI - Diritto Amministrativo vol. II — ano acadêmico 1946-1947, p. 41; FRANCESCO D'ALESSIO - Diritto Amministrativo - volume II - 1943 - p. 153).

O episódio central da história administrativa do século XIX é a subordinação do Estado ao regime da legalidade. A lei, como expressão da vontade coletiva, incide tanto sobre os indivíduos como sobre as autoridades públicas. A liberdade administrativa cessa onde principia a vinculação legal. O Executivo opera dentro em limites traçados pelo Legislativo, sob a vigilância do Judiciário.

A esse fenômeno de legalização da atividade administrativa associou-se, a seguir, a tendência do fortalecimento do Poder Executivo. A sociedade liberal, baseada na livre iniciativa, aprofundou-se em contradições e antagonismos. Os interesses se organizaram em grupos, provocando conflitos intoleráveis com os postulados da ordem democrática. O Poder Público foi convocado a disciplinar e conter a atividade privada, sujeitando-a aos princípios do bem comum e da justiça social. O Estado moderno assumiu, nesta fase, sentido dinâmico, mediante a regulamentação, o controle ou o monopólio do comércio, da produção, do ensino, do transporte ou, até mesmo, da pesquisa científica. A tônica dos regimes políticos se deslocou da abstenção para a intervenção. Intervir para preservar - era o lema democrático.

Os novos encargos de governo levaram à hipertrofia dos órgãos executivos. Não mais se limitava a administração ao papel clássico de manter a ordem e a tranqüilidade públicas. O poder de polícia do Estado alcança, praticamente, todas as formas de atividade humana. A administração, ao mesmo tempo, se especializa e se generaliza. Os entes estatais se descentralizam em novas pessoas jurídicas de direito público. A capacidade normativa do Executivo se desenvolve por meio das delegações legislativas e do poder regulamentar. Os tribunais administrativos, ou as comissões dotadas de poderes quase judiciais, englobam expressiva parcela da atividade jurisdicional.

O individualismo jurídico se decompõe sob a pressão poderosa de causas e concausas sociais. A socialização do Direito transcende ao plano doutrinário e se afirma na criação legislativa e na hermenêutica constitucional. Não se trata apenas - disse-o o professor Afonso Arinos de Melo Franco - de crise do Direito, mas de Direito da crise.

As condições sociais atribuem ao Estado uma posição de tutela e gerência de interesses gerais e individuais. A manutenção e sobrevivência do indivíduo, a sua proteção contra riscos e incertezas sociais, a própria defesa da soberania nacional motivam a revisão de alicerces: a propriedade, a família, o trabalho, a autonomia da vontade ou a liberdade de contrato obedecem a novos pressupostos de inspiração coletiva.

Conquistada a autonomia do Direito Administrativo, o conceito de serviço público se concentra no exercício das atividades essenciais do Estado, dotado de personalidade jurídica de direito público, em termos unitários. Gradualmente, porém, a 
presença do Estado em outros ramos de atividade, de natureza econômica ou social, conduz a que a lei venha a instituir outras pessoas jurídicas subordinadas, com atribuições específicas. O serviço público, em sentido lato, passa a desdobrar-se entre a Administração Direta, que tem como sujeito ativo o próprio Estado, e a Administração Indireta ou Descentralizada, na qual se inscrevem pessoas administrativas, dotadas de personalidade jurídica própria, embora sob controle do poder central.

O processo descentralizador, que visa a propiciar condições operacionais mais flexíveis, primeiramente se define na criação de Autarquias, pessoas jurídicas de direito público, de finalidade especial, em áreas definidas de competência.

Em outro momento, o processo de intervenção estatal amplia a atividade administrativa, assumindo o Estado áreas até então reservadas à economia privada. A lei administrativa, atendendo a este objetivo, vai buscar, no plano do direito privado, o modelo das sociedades mercantis, compondo em termos competitivos, ou excepcionalmente em grau de monopólio, a modalidade de sociedades de economia mista, como outra forma integrante da Administração Pública Indireta. Na prática da atividade mercantil a empresa paraestatal se equipara à empresa privada, não obstante a ela se sobreponha, necessariamente, o controle superior do Estado de modo a preservar a destinação da política administrativa que é o objetivo final da criação legislativa. A empresa estatal, mais do que um fato econômico, é um fato político.

De forma distinta, se constituem, ainda, à margem do esquema da Administração Pública, determinadas atividades de interesse coletivo, notadamente no campo da cultura e da assistência social, que merecem o amparo e proteção do Estado, como entes de cooperação, para o desempenho de serviços de utilidade pública, sem caráter econômico. Assumem a natureza jurídica de Serviços Sociais Autônomos, com personalidade de direito privado, que embora não integrando a Administração Pública são beneficiários de contribuições ou recursos públicos.

A crescente política de socialização, caracterizada pela exacerbação da presença do Estado no domínio público, que marcou a tendência na fase de após guerra, conduziu ao fenômeno de maior concentração do Estado na gestão da atividade produtiva que BILAC PINTO caracterizou em estudo clássico sobre " $O$ declínio das sociedades de economia mista e o advento das modernas empresas públicas" (Revista de Direito Administrativo - vol. 32, p. 1 e ss.). De igual modo, a ampliação da política do Estado empresário se fez sentir na encampação de concessões de serviço público, em grande parte motivada pelo decréscimo qualitativo gerada pela insuficiência tarifária.

A ordem de grandeza das empresas estatais, na década de 80 , pode ser mensurada à luz do recenseamento feito, nos termos do Decreto n. 84.128, de 29 de outubro de 1979, pela Secretaria de Controle de Empresas Estatais, como órgão central do sistema de controle de entes descentralizados.

O cadastramento editado em setembro de 1981 contempla um universo de 530 empresas da União. Excluídas desse número as pessoas jurídicas sob forma de autarquias, fundações ou órgãos parafiscais, ainda assim restarão 360 pessoas jurídicas constituídas sob forma societária de $1^{\circ}$ grau ou subsidiária, nas quais prevalece o capital público (ver nosso livro Temas de Direito Público, volume I, p. 818/819 e, ainda, na p. $679 \mathrm{e} \mathrm{s.} \mathrm{o} \mathrm{estudo} \mathrm{sobre} \mathrm{"As} \mathrm{empresas} \mathrm{estatais} \mathrm{no} \mathrm{direito} \mathrm{brasileiro").}$ 
A partir da Constituição de 1988 - e como reflexo de uma diretriz marcante no campo do direito comparado - evidencia-se uma nítida inversão na política intervencionista do Estado com o retorno da iniciativa privada a áreas ocupadas pela gestão estatal, marcando o fenômeno que, no direito espanhol, foi batizado como a "fuga do Direito Administrativo" (ver, entre outros, MARTIN RETORTILLO - Reflexiones sobre la "huida" del Derecho Administrativo - in Revista de Administración Pública - vol. 140 - maio-agosto 1996, p. 25 e s.).

O primeiro passo, ainda modesto, de retração da tendência expansionista da Administração Pública Federal se manifesta, entre nós, em julho de 1979, com a adoção do Programa Nacional de Desburocratização (Decreto n. 83.740), aperfeiçoado com a criação do Conselho Interministerial de Privatização, em 1988 e com o advento do Programa Nacional de Desestatização, mediante a Medida Provisória n. 155/90, convertida na Lei n. 8.031 , de 12 de abril de 1990, que firma o padrão da política de privatização, em continuada execução (ver, a respeito, nosso estudo sobre "O retorno do pêndulo: serviço público e empresa privada" in nosso livro Temas de Direito Público, volume I, p. 721 e s.).

A iniciativa econômica pública, por definição constitucional, se destina a complementar a iniciativa privada, obedecendo ao princípio da subsidiariedade, restringindo-se a exploração direta da atividade econômica pelo Estado à prevalência da segurança nacional ou a relevante interesse coletivo determinado em lei (Constituição, art. 173).

O novo modelo do Estado Democrático de Direito estimula a harmonia entre a atividade estatal e a ação privada, valorizando os entes de cooperação e fortalecendo o desenvolvimento da comunidade mediante os instrumentos de garantia e proteção de direitos coletivos e difusos.

A associação entre o serviço público e a atividade privada acrescenta ao instrumento tradicional da concessão ou permissão os novos parâmetros de consórcio e de parceria, excelentemente estudados por ARNOLDO WALD e outros, como por MARIA SYLVIA ZANELLA DI PIETRO em monografias especiais sobre o tema caracterizando o estilo moderno do Direito Administrativo participativo, ao qual dedicamos estudo recente (Revista de Direito Administrativo - vol. 209, julho-setembro 1997, p. 1 a 6).

Acentuamos, na oportunidade, que "o Direito Administrativo contemporâneo tende ao abandono da vertente autoritária para valorizar a participação de seus destinatários finais quanto à formação da conduta administrativa. O Direito Administrativo de mão única caminha para modelos de colaboração, acolhidos em modernos textos constitucionais e legais, mediante a perspectiva de iniciativa popular ou de cooperação privada no desempenho de prestações administrativas".

Em figurinos atuais, a legislação federal adiciona novas técnicas de cooperação entre o Estado e a atividade privada, delegando-se a esta última a execução de serviços públicos, mediante contratos de gestão ou esquemas de terceirização.

Em experiências legais mais recentes, a política de privatização se complementa com a atribuição de diretrizes de política administrativa a agências reguladoras, do- 
tadas de competência de supervisão da atividade privada. O Estado, em suma, se retira do plano da gestão direta dos serviços, recolhendo-se a uma posição de avaliação da eficiência dos agentes privados, com vistas a proteger o interesse dos usuários.

A Medida Provisória 1.648-7, de 23 de abril de 1998, que substituiu a Medida Provisória n. 1.591, qualifica como Organizações Sociais pessoas jurídicas de direito privado, sem fins lucrativos dirigidas a atividades de ensino, cultura e pesquisa científica, ou de desenvolvimento tecnológico, bem como à proteção e preservação do meio ambiente ou à saúde. Sobre o teme merece referência o valioso estudo de DIOGO DE FIGUEIREDO MOREIRA NETO (Organizações Sociais de Colaboração Revista de Direito Administrativo, volume 210 - outubro-dezembro 1997, p. 183 e s).

ALICE GONZALEZ BORGES, destacou, como forma de colaboração, o modelo de arrendamento de áreas portuárias, conforme a Lei n. 8.630, de 25 de fevereiro de 1993 e o credenciamento para operações de segurança veicular (Repertório de Direito Administrativo — edição da Nova Dimensão Jurídica — vol. I — 1997 — p. 21 e ss.).

De outra parte, os sistemas de cooperação e de intercâmbio não são mais tãosomente um fenômeno de âmbito nacional. Os acordos internacionais se ampliam em estruturas institucionais que configuram, como bem assinala ARNOLDO WALD, parcerias regionais, que tendem a compor unidades econômicas, como o Mercosul, a União Européia ou a NAFTA, em variados estilos de globalização.

JUAN CARLOS CASSAGNE, em valioso estudo comparativo à luz da experiência argentina, particularizou a adaptação do serviço público aos modernos sistemas de economia de mercado (El ressurgimento del servicio publico y su adaptación en los sistemas de economia de mercado - hacia una nueva concepción) - Revista de Administración Pública - vol. 140 - maio-agosto 1996 - p. 95 e s).

Superando limites geográficos, o Direito Administrativo Internacional desvenda, assim, novos rumos de integração no duplo sentido de cooperação entre os poderes públicos e a iniciativa privada como especialmente a associação de Estados soberanos no caminho da colaboração administrativa e da associação econômica e social.

Este se desenha, na criatividade das experiências, o sentido do Direito Administrativo do novo século tanto no plano interno como na transcendência das fronteiras.

Coincidem, em suma, no término do século atual, uma relativa retração do Estado no plano interno e a expansão de experiências de unificação no campo internacional.

Privatização e globalização são dois fenômenos de uma nova era.

Paralelamente, as Constituições mais recentes prestigiam a proteção da cidadania, revitalizando os clássicos princípios da liberdade, igualdade e fraternidade.

Esta é a incógnita do Estado futuro em que cumpre aos juristas encontrar o estilo idea! do casamento entre a soberania nacional e a comunhão internacional, do qual nascerá o Direito Administrativo de amanhã. 
Abuso do Direito nos Contratos de Consumo

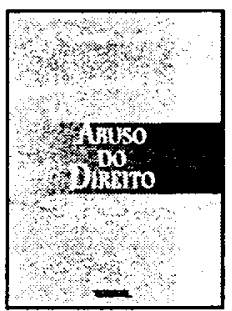

Heloisa Carpena
Ref. 0344
Brochura
271 págs.
Form. 14×21
2001
ISBN $85-7147-290-4$

Esta obra compreende o estudo do abuso do direito, desde as origens do instituto até sua aplicação pelos tribunais brasileiros. A teoria do ato abusivo é analisada como fenômeno de relativizaçāo dos direitos subjetivos, que passam a ser funcional izados de acordo com os princípios que regem e fundamentam o ordenamento jurídico, dentre eles, o da dignidade da pessoa humana.

\section{A Responsabilidade Civil do Fornecedor de} Produtos pelos Riscos do Desenvolvimento

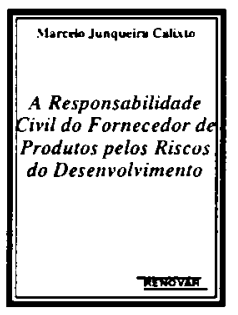

Marcelo Junqueira Calixto

Ref. 507

Brochura

278 págs.

Form. $13,5 \times 21$

2004

ISBN 85-7147-451-6

São analisados aqui os conceitos fornecidos pelo Código de Defesa do Consumidor e os pressupostos da responsabilidade do fornecedor, quais sejam, 0 defeito do produto, o dano e o nexo causal entre defeito e dano. Passando ao estudo das excludentes de responsabilidade, a dissertação encontra o seu tema central no exame de uma possivel excludente, aquela fundada nos chamados riscos do desenvolvimento.

\section{O Abuso do Direito e as Relações Contratuais}

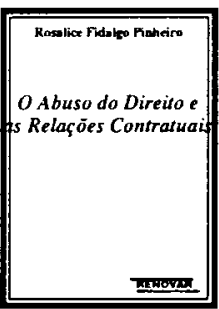

\author{
Rosalice Fidalgo Pinheiro \\ Ref. 0402 \\ Brochura \\ 464 págs. \\ Form. $13,5 \times 21$ \\ 2002 \\ ISBN $85-7147 \cdot 835 \cdot X$
}

Ao fixar sua análise no campo das relações contratuais, a autora identifica na autonomia privada e no direito subjetivo cristalizados em torno de interesses individuais os elementos de base para o desenvolvimento do abuso do direito. A percepção da doutrina, no que se refere à dificuldade de uma definição atual do abuso do direito, serve-the de impulso para que examine, criticamente, a metodologia clássica do direito privado.

\section{Direito do Consumidor na Era da Globalização A descoberta da cidadania}

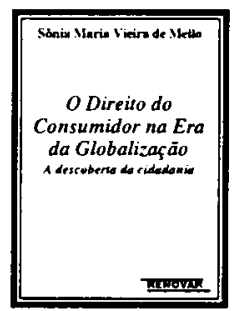

Sónia Maria Vieira de Mello

Ret. 0180

Brochura

172 págs.

Form. $13,5 \times 21$

1998

ISBN 85-7147-088-X

Neste livro, a autora expõe como o consumidor, nesta era de produção global, torna-se consideravelmente vulnerável diante das práticas perpetuadas pelos fornecedores de bens e serviços, muito mais bem informados, fundamentados e assessorados, para os embates mercadológicos. Por fim, analisa as perspectivas que se abrem aos consumidores no Mercosul e em nivel internacional. 